\title{
Description of Manuscript Collections; A Single Network System
}

\begin{abstract}
This system uses the Inventory/Guide and Cumulative Indexes for names, subjects, and chronology. Name control normally is keyed to the file folder level, while subject and chronological control are keyed to the level of the manuscript group. The system capitalizes on the methodology of researchers, who normally will have associated names with special and personalized aspects of their subject prior to their using manuscript and archival materials. Name control becomes the key to specialized subject control. Narrative description is kept to a minimum, and is concentrated in the guide section of the $I / G$.
\end{abstract}

$T_{1}$ lined in this article is based on the following elements:

1. that the record items comprising manuscript groups have serial characteristics, and that this feature should be the basis of both their arrangement and description;

2. that users of manuscript collections normally approach their subject by having previously associated it with names: personal, corporate, and geographical;

3. that this name/subject association on the part of the researcher is so specific and special as to justify a minimal effort at subject analysis on the part of the describer;

4. that comprehensive bibliographical control of the manuscript collection as a whole is preferable to a minute bibliographical control of single manuscript items, or of only a fraction of the manuscript groups that

Mr. Berner is Archivist and Mrs. Bettis is Curator of Manuscripts at the University of Washington Libraries. comprise the manuscript collection;

5 . that narrative or synoptic description of items is of little value to most researchers, particularly if such description is at the expense of useful comprehensive description for other manuscript groups in the collection;

6. that individual Inventory/Guides or Registers which are cumulatively indexed for names, subjects, and chronology should constitute the finding aid network for the entire manuscript collection, a single descriptive system.

Before proceeding to an outline of this single finding aid network, some reference to arrangement of manuscript groups is essential. First, in conformity to the principle of provenance, manuscripts are kept together according to the source that generated them. ${ }^{1}$ In addition, the existing order of any fresh

\footnotetext{
1 The principle of provenance is the basis of archival practice, and because manuscript groups, like archival record groups, are themselves composed of record items normally appearing in some order, they should be organized and described by archival techniques. These items are either in some filing order, or can be placed in one according to their inherent serial characteristics.
} 
acquisition may already have some ordered arrangement, or it may not. If it does have one, it will be inevitably in serial form. If it does not have one, it should be arranged serially because the activity reflected in the manuscript documentation itself will have occurred serially, not randomly; and both description and retrieval will be made easier. Furthermore, even if items are not placed in an order according to their serial characteristics, they must be placed in file folders eventually for ease of description and retrieval. The folders themselves then can be numbered serially. The main reason, however, for seeking a serial arrangement instead of merely accepting or placing items in random order is that the relatedness of the documentation in the items will be more readily apparent when placed in proximity to other items that reflect any given line of thought or activity. In brief, action occurs serially, therefore the documentation is itself best arranged serially to reflect the line of action.

Record series are of many kinds depending largely on the form of the item(s). There will be, for example, correspondence (general, incoming and outgoing, and some memoranda), reports, minutes, various kinds of business records such as journals, ledgers, profit and loss statements, etc. Once the given manuscript group has been arranged, it is ready for description.

The kind of description can be in some variant of traditional library cataloging practice and can be done on catalog cards $^{2}$ that are often supplemented with other descriptive apparatus, or it can be done by the method advocated here, or a variant thereof, a single finding aid network. If by a traditional method, there will be an attempt at description of individual items

${ }^{2}$ See the Anglo-American Cataloging Rules, pp. 259-71. and selective cataloging of items deemed special. If by the latter, the description will be keyed to serial characteristics instead of items.

This network is analogous to that represented in the National Union Catalog of Manuscript Collections. It has, like the NUCMC volumes, cumulative indexes to names and subjects, but it has also an index to chronology. The crucial difference lies in the fact that the network is keyed to controls at the repository level, while NUCMC is keyed to the national level. In the network, index entries refer not to a catalog entry, but to the Inventory/Guide (or Register) for the particular manuscript group. In the $\mathrm{I} / \mathrm{G}$, in turn, the user will be referred to the particular container and file folder in which the item(s) is(are) stored. Just as in NUCMC there is a minimum of description, here also there are only the same kind of skeletal name and subject leads appearing in the cumulative index. These, in turn, refer the user to the I/G for the particular manuscript group. The guide section will contain whatever substantial narrative description there is, and will have the same elements in it that occur in NUCMC entries; but because space is less of a factor, there can be considerably more detail along with some additional narrative about the basic arrangement or layout of the manuscript group.

The guide section can be organized uniformly for all inventories, or it can be composed of differing and distinct elements, depending upon the manuscript group being inventoried. Some of the more typical elements of a guide include: biographical outline of the person, or historical sketch of the corporate body; chronology (of major events); genealogy (if clarification is helpful as in the case of family papers); provenance, telling about source, organic relation to other manuscript groups in collection, organic evolution of the papers; description of records (brief phys- 
ical description indicating size of the manuscript group, types of records, etc.); general information (concerning overall arrangement of the manuscript group, significant features, abbreviations, etc.).

This guide section is then followed by the inventory proper. It is in the inventory that the whereabouts of the item(s), file folder(s), or series will be indicated. The inventory section will vary according to the arrangement of the different manuscript groups, for the arrangement, as noted above, will depend upon an original order if there was one or upon one devised by the repository.

The correspondence series normally is the most important one because letters tend to reflect most accurately the motives of the participants in an event or development. It is from the conflict of motives and ideas that decisions are shaped and made part of the historical and social process. Other record series lend documentary support to the correspondence series, although they will have an independent significance as well. The correspondence series is also crucial in another respect, for it is through this series that the control of names represented in the manuscript group is most easily established. Correspondence also is, or can be, the most variable in arrangement, being sometimes in a chronological order, or a chronological-alphabetical order, or by subject, or by a numerical scheme, or combinations of these. Shown below are representative examples of the more common arrangements and inventory descriptions of the correspondence series. Description of other series will be referred to after correspondence has been covered.

In some repositories, if the original order of a new accession is unworkable or in disarray, the incoming correspondence will be arranged alphabetically by correspondent, and the outgoing, chronologically, thereby providing a dual approach to the manuscript group.
In the example that follows, box and folder number are indicated as are the inclusive dates of the correspondence and the exact or approximate number of items. In this particular example the authors represented in the miscellaneous folders are also noted because they are deemed significant. All of these names or just those in the individual name folders can be entered in a Cumulative Name Index (CNI) of the repository. Thus, a user trying to locate information about James R. Barnes will be searching for material written by him and persons and organizations associated with him. From these leads he will progressively fan out. It is the CNI that provides these name leads by referring the researcher to the I/Gs for each of the manuscript groups listed under the name entry in the CNI. In turn, the inventory will indicate the particular box and folder having letters, for example, of James R. Barnes. Once he has read these he will then fan out in the manuscript group and in the manuscript collection as a whole according to the additional leads that he picks up. Proceeding from the resources of this one repository he can then consult NUCMC and move on from there in similar fashion. See Example 1.

By this alphabetical arrangement an objective basis for listing names of correspondents has thus been prepared. Furthermore there is normally a coincidence of a given name as both author and recipient in the correspondence series. Therefore it is largely unnecessary to list him where he is the recipient if he is already listed as author, for the researcher will usually be able to locate such letters easily. References to the name as recipient can be made but this requires the listing of individual letters, because they would be in the outgoing letters series which is arranged chronologically. To do so would, of course, give a more completely objective name control but at much greater ex- 
EXAMPLE 1

INCOMING LETTERS

Box/folder no.
$1 /(2-11)$
$1 / 12$
$1 / 13$
$1 /(14-16)$

\begin{tabular}{l}
\multicolumn{1}{c}{ Name } \\
Beck (R. W.) \& Associates \\
Bone, Homer Truett \\
Brazil, Chesley \\
B Miscellaneous \\
Bancroft-Whitney Company \\
Barnes, James R. \\
Batcheller, Willis T.
\end{tabular}

Name

Bone, Homer Truett

Brazil, Chesley

Bancroft-Whitney Company

Barnes, James R.
Batcheller, Willis T.

$\begin{gathered}\text { Inclusive } \\ \text { dates }\end{gathered}$
$1937-1942$
1941,1942
1937,1938
1944
1940
1943

Approx. (or exact) No. of items

165

7

32 pense, an added cost that the researcher probably does not require in order for him to find the pertinent items.

In general, reasonably objective listing can be achieved simply by author control in the incoming letter series. If it is decided, at the conclusion of processing a given manuscript group, that names as both author and recipient tend to coincide, the outgoing letters series can be described simply:

\section{EXAMPLE 2}

OUTGOING LETTERS

$\begin{array}{ccc}\text { Box/folder no. } & \begin{array}{c}\text { Inclusive } \\ \text { dates }\end{array} & \begin{array}{c}\text { No. of } \\ \text { items }\end{array} \\ 24-(12-38) / 25-(1-13) & 1937-1944 & \text { ca. } 465\end{array}$

In the case in which incoming and outgoing letters are kept together as general correspondence, objective name control is more difficult unless the general correspondence is arranged alphabetically by year or periods. Records of corporate bodies are often received in this order; as such, it is an easy one to describe, like any alphabetical arrangement. However, in cases where the general correspondence is in a chronological order, name control tends to be more subjective, posing a problem similar to that in reporting names of major correspondents to NUCMC or in any system that features a high degree of selectiveness.

In cases where incoming and outgoing letters have been filed together in chronological order, several avenues of approach are open depending upon the content and importance of the manuscript group and depending upon the anticipated demand. For example, the description can be either very general and keyed to the series level ${ }^{3}$ like:

\section{EXAMPLE 3}

GENERAL CORRESPONDENCE SERIES

$$
\begin{array}{ccc}
\text { Box/folder no. } & \begin{array}{c}
\text { Inclusive } \\
\text { dates }
\end{array} & \begin{array}{c}
\text { No. of } \\
\text { items }
\end{array} \\
1 / 1 \text { to } 3 / 28 & 1942-1951 & \text { ca. } 1050
\end{array}
$$

Major Correspondents Include:

Asice, Benjamin S.

Bartley, Bruce

Beck, Robert W.

Block, Robert J.

Chase, Goodwin

Clark, Irving

Davis, James

Duecy, Georg P.

or the description can be more precise and keyed to control at the folder level like:

\section{EXAMPLE 4}

GENERAL CORRESPONDENCE SERIES

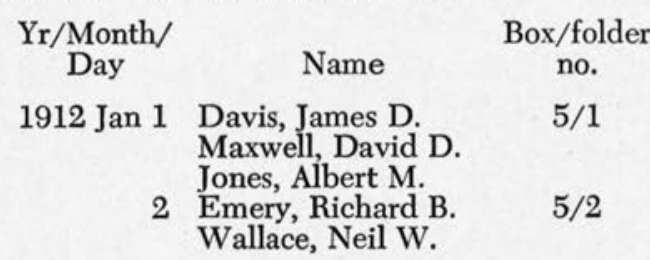

Another common filing arrangement for general correspondence is that in

${ }^{3}$ Oliver Wendell Holmes, "Archival ArrangementFive Different Operations at Five Different Levels," American Archivist, XXVII (January 1964), 21-24. 
which subject and name folders are either mixed or separated, one into a subject series and the other by name of correspondent. It is the subject series that poses the special problem of control. This series typically contains correspondence, clippings, reports, leaflets, pamphlets, etc. If the original arrangement is kept, the file folder for that subject can be redistributed into several sub-folder units according to record type while retaining the original subject arrangement or kept randomly as they appear within that arrangement. The inventory description can be like Example 5 in a Congressman's papers: that are underlined will be entered in the CNI. Note that both geographical and personal names are selected. The matter of subject headings will be discussed later.

Interoffice correspondence is a relatively simple matter as it normally is filed according to offices or persons within an organization and filed chronologically therein, or else it will be in an undifferentiated straight chronological order. If the arrangement is the latter, it is adequate and effective simply to list the principals involved. If the arrangement is by office or person and chronological within, the inventory de-

\section{EXAMPLE 5}

$\begin{array}{ccc}\begin{array}{c}\text { Box/folder no. } \\ 10 / 3-6\end{array} & \begin{array}{c}\text { Subject } \\ \text { Hells Canyon }\end{array} & \begin{array}{c}\text { Inclusive } \\ \text { dates }\end{array} \\ 10 / 7 & 1946 \\ 10 / 8 & \text { Japan } & 1952 \\ & \text { Home rule-D.C. } & 1950\end{array}$

\begin{abstract}
Contents
Correspondence with Gus Norwood, Richard Neuberger, National Hells Canyon Assn; reports, speeches, clippings.

Correspondence with Miller Freeman, Alaska Fishermen's Union; reports, speeches, clippings re Alaska fisheries.

Correspondence with John F. Kennedy.... .
\end{abstract}

However, because names in the above examples will be scattered randomly throughout a subject series, a name index for the inventory must be made. scription can be like Example 6 for a lumber firm. These names would all appear in the CNI.

Memoranda series are akin to inter-

\section{EXAMPLE 6}

$\begin{array}{clcc}\text { Box/folder no. } & \text { Name } & \text { Year } & \text { Items } \\ 51 / 10-20 & \text { Griggs, Everett G., Pres. } & 1920 & \text { ca. } 100 \\ 21-40 & & 1921 & \text { ca. } 150 \\ 53 / 6-10 & \text { Jacobson, Norman G., Forester } & 1920 & \text { ca. } 50 \\ 11-17 & \text { Wagner, Corydon G., Vice-Pres. } & 1921 & \text { ca. } 75 \\ 55 / 1-5 & \text { ca. } 75\end{array}$

One can also be made for subjects for the inventory itself although subjects cannot be incorporated into the CSI without first being converted into standard headings, while the names can be entered directly into the CNI. From this description in the inventory, the names office correspondence and can be handled in much the same way.

With some exceptions ${ }^{4}$ name control

\footnotetext{
${ }^{4}$ Court papers, legal briefs and ephemera, speeches and writings of others, are exceptions inasmuch as names as both subjects and authors are of central concern.
} 
is not the key to controlling other record series. Inasmuch as most other series document almost exclusively a single aspect of the overall activity of the person or organization, a chronological arrangement by series is both normal and easily described. Some examples are financial record series, minutes of meetings, and internal reports. However, if other parties (corporate or personal) have generated any record series or have activity that is primarily reflected (as in subgroups), name control should be of central concern again.

For example, if a person has included with his personal papers those of organizations with which he has been associated, subgroups should be established, if possible, for the record series of these organizations. By establishing organic subgroups there is meaningful conformity to a sound archival principle, that of provenance. And for the same reasons as for the manuscript group as a whole, this subgrouping is justified because it will reflect directly the serial evolution of that subunit's activity, and description is made easier as well. Thus, Corydon Wagner's papers include, besides his personal papers, those of the West Coast Lumbermen's Association, of the National Lumber Manufacturers Association, and of the Chamber of Commerce of the United States. $\mathrm{He}$ was an official in each. In each of these organic subgroups are the usual kinds of records series: correspondence, reports, minutes, etc. Each subgroup is described in the same way as an undifferentiated manuscript group, that is, one without subgroups. However, because of the complexity added by having to subgroup the papers, it is best to have a name index to the inventory showing on which pages of the inventory names may be found. This name index can, in turn, be used for entering them into the CNI.

Some special attention is merited by the ephemera series. Ephemera are short-lived items such as pamphlets, leaflets, and broadsides generated in the heat of controversy; consequently, they have considerable historical value for the decisive way that they will often affect an event. Names of sponsors and publishers are often as important as personal authors represented on the same item, for ephemera are commonly generated by organizations, and personal authorship can be of less significance than that of the publisher or sponsor. All three kinds of names should be noted in the inventory and hence in the CNI. If there is a title, it can also be noted in the inventory, and if it is deemed sufficiently important or unique, there is no reason not to include the title in the CNI, as it can be placed easily into the alphabetical sequence of the index. Because a person or corporate body will often generate its own ephemera and receive it as well, the ephemera series can be divided into two subseries, one for its own, and one for other parties. The latter should be arranged alphabetically by either personal author or corporate author, sponsor, or publisher and described accordingly.

\section{Subject Headings}

Bearing in mind the function that name control plays in enabling the researcher to locate manuscript and archival material relating to his subject, some discussion of subject headings is relevant at this point.

Through the use of names, particularly personal and corporate, the researcher is keyed to individual file folders and to record series in the manner described above. Specific subject content is inferred by the name/subject association on the part of the researcher. It is up to him to check this inference by going to the individual file folders and record series to find out for himself the actual subject contents of the items found therein. 
Of course the compiler of the inventory could attempt a minute subject analysis keyed to the item or the file folder level or to some grosser level, but where should the analysis and description stop? And should it be done with approximately equal weight and quality for each manuscript group in the collection? Will a subject reference made to one item or file folder be referred to when that subject occurs elsewhere? If not, what is to prevent the researcher from believing that he has exhausted all the material in the collection when he has consulted all subject references made in the findings aids of the repository? Will a new subject heading be retroactive and retrospective in its application? If the answer to these and related questions is largely negative, an alternative should be sought.

One alternative is to use broad subject headings for each of the main lines of human activity and relate these headings to the level of the manuscript group as a whole, not to the items or file folder units or series that make it up. Subject headings would characterize the main lines of activity reflected in that manuscript group. In establishing subject headings at the manuscript group level, and relying upon the name/subject association by the researcher as the main method of leading him to his specialized subject matter, the compiler of the inventory will largely avoid the pitfalls in traditional subject analysis. As there is need for experimentation in this troublesome area, no specific system is recommended here. However, the one being experimented with at the University of Washington is suggestive because it is an outgrowth of the name/ subject association approach to manuscript and archival material. Briefly, it uses fourteen major subject headings for main lines of human activity, followed normally by one subject subdivision, fol- lowed by one for geographical place name. ${ }^{5}$

The above network system is based upon observation of the methods and techniques usually employed by researchers in their use of manuscript collections and archives. A researcher will already have read the published material relating to his subject. In the course of this reading he will have defined more precisely what aspect of it requires his attention, and he will minimize the hazard of duplicating what has already been done. He will also have read certain primary sources such as newspapers, government documents, pamphlets. In the course of this preliminary research he will have associated names of persons and organizations with his particular subject. He will, in fact, have done this so precisely and in so personal a manner that no describer of the manuscript group would be able to anticipate his needs. Whatever painstaking subject analysis of items and series that the describer might make would be largely a superfluous substitute for that minute name/subject association developed inherently by the researcher in his preliminary study.

A further consideration for the describer is that if he seriously attempts a minute subject analysis he will find himself bogging down into a description of individual items and selecting some bibliographic clues for mention while ignoring others. If this is done at the expense of establishing controls over other manuscript groups in the collection, it is largely without justification.

With this in mind it is clear that the kind of bibliographical control to be sought should: 1) have a high degree of name control, thereby capitalizing on

${ }^{5}$ Those fourteen headings are: agriculture, art, commerce, education, industry, international relations, labor relations, literature, politics and government, population, religion, science, travel, and war. Their use is defined by scope notes. 
the basic methodology of researchers; and 2) employ subject control keyed to manuscript group level, not at the file folder or item level.

To employ the network system the following elements are used:

\section{Cumulative Name Index}

Index to all personal, corporate, geographical names deemed significant. May include titles of items as well.

\section{Cumulative Subject Index}

Index to subject matter that is characteristic of each manuscript group and its subgroups, but not of its component items and series.

\section{Chronological Index}

Index listing manuscript groups which fall within a particular time span (year or period).

\section{Inventory/Guide or Register}

The three (3) cumulative indexes are keyed to and derived from the individual I/Gs or Registers.

\section{Basic Data Sheet}

Data includes name of manuscript group, date span, type of material, location within repository, size, donor and date of acquisition. Supplementary information can include major correspondents, significant biographical features, restrictions, literary property rights, and subjects covered. This is made up at time of accessioning and can have tentative subject headings. Serves as a preliminary I/G.

A researcher seeking available information on a given problem can approach it through the use of the Cumulative Name Index, the Cumulative Subject Index, or the Chronological Index. If, for example, the researcher is developing a study of the Seattle General Strike (February 1919), he normally would have read newspaper and other eyewit- ness accounts as well as most secondary source materials prior to using the primary materials of the manuscript repository. From this reading he would have learned the names and dates and determined the special aspects of his subject requiring investigation. His basic approach may be by way of year (1919) using the chronological index, by subject (Labor relations-strikes-Washington and Politics and government-Washington-Seattle) using the CSI, or by name (in Example 7, Wesley L. Jones) in the CNI. It is through these indexes that the researcher is led to the appropriate I/Gs and from them to the particular materials desired.

Examples 7, 8, and 9 illustrate that each of these cumulative indexes will lead him to the Erastus Brainerd papers. The CNI sheet (Example 7) indicates that material concerning Wesley L. Jones can be found in the papers of Erastus Brainerd, Miller Freeman, the St. Paul and Tacoma Lumber Company, and many other manuscript groups. The Brainerd papers also are listed in the CSI (Example 8) and in the Chronological Index (Example 9). However, because only a few items in the Brainerd papers touch upon the strike, his papers would not be listed under "Labor relations-strikes-Washington." The reason for this is that subject headings are keyed to the level of the manuscript group, not to items or series. Brainerd was a newspaper editor active in Republican politics who had only an incidental connection with the strike. However, by contrast the papers of James Duncan, a strike leader, relate directly to the strike, so his papers will be listed under "Labor relations-strikes -Washington" as well as under "Politics and government-Washington-Seattle."

Following the lead in the CNI the researcher might especially want to see the correspondence of Wesley L. Jones in the Brainerd papers. By viewing the 


\section{EXAMPLE 7}

Examples are one-half actual size. Inclusive dates refer to time spanned by manuscript group.

JONES, Wesley Livsey, 1863-1932

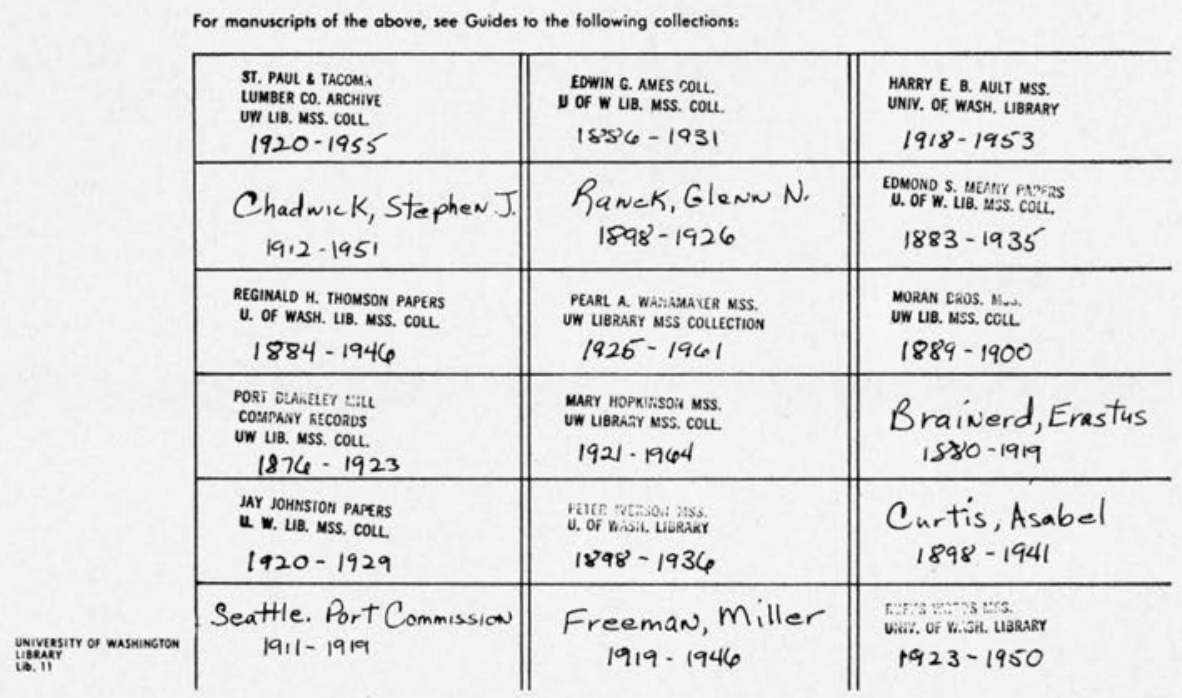

EXAMPLE 8

Politics and government - Washington - Seattle

For manuscripts relating to the obove SUBJECT see Guides to the following collections:

\begin{tabular}{|c|c|c|c|}
\hline & $\begin{array}{l}\text { ELMER MILLR PAPERS } \\
\text { U OE W LI. MSS. COLL } \\
1931-1964\end{array}$ & $\begin{array}{l}\text { mice c. TO: uefson uss. } \\
\text { u of w uz. Liss. coul. } \\
1954-1964\end{array}$ & $\begin{array}{l}\text { ANIT-QCE } \\
\text { U. Of WASY US. ASSS. COLL } \\
1942-1955\end{array}$ \\
\hline & $\begin{array}{c}\text { MENRY SCHMITZ PAPERS } \\
u \text { OF W UB. MSS. COLL. } \\
1930-1965\end{array}$ & $\begin{array}{l}\text { Brainerd, Emastus } \\
1880-1919\end{array}$ & $\begin{array}{l}\text { Lockwood, Envid E. } \\
193.3-19.38\end{array}$ \\
\hline & $\begin{array}{l}\text { SIDNEY GERSER PAPEAS } \\
U \text { OF W UB. USS. COLL. } \\
1942-1965\end{array}$ & $\begin{array}{l}\text { EWEN C. DIEGWALL MSS. } \\
\text { U OF W UB. }=55 \text {. coll. } \\
1957-1962\end{array}$ & $\begin{array}{l}\text { Wolfstone, Michael } \\
\text { V.f. } 1407 \quad 1933-1938\end{array}$ \\
\hline & $\begin{array}{l}\text { Coe, Earl S. } \\
1939-1956\end{array}$ & $\begin{array}{l}\text { GUS NOSWOOD PAPERS } \\
\text { U OF } W \text { UIB. USS. COLL. } \\
1948-1966\end{array}$ & $\begin{array}{l}\text { Gorsov s. cunton mss. } \\
\text { u. of w. L8. uss. coll. } \\
1956-1964\end{array}$ \\
\hline & $\begin{array}{l}\text { Jaxes 1. CEPRCHTY MSS. } \\
\text { U. Of W. U8. NSS. COLL. } \\
1924-1932\end{array}$ & $\begin{array}{l}\text { Bonk, Homer t. } \\
1936-1945\end{array}$ & \\
\hline 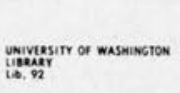 & $\begin{array}{l}\text { Mcclan, Berward } \\
\text { v.f. } \$ 403 \quad 1933-1938\end{array}$ & $\begin{array}{l}\text { Ballinger, Fichand A. } \\
\text { 1907-1922 }\end{array}$ & \\
\hline
\end{tabular}

Name Index to the Brainerd Inventory (an index to the I/G itself is necessary wherever a name appears randomly or in more than one unexpected place in the $I / G)$ he will find that the name
Wesley L. Jones appears on pages 7, 9, 12 , and 16 of the inventory (Example $10)$. Information on page 7 of the inventory shows that 115 letters were written by Jones to Brainerd between the 
EXAMPLE 9

\begin{tabular}{|c|c|c|}
\hline \multicolumn{3}{|c|}{ For manuscripts writion in the obove YEAR, nee Guiden to the following colloctions: } \\
\hline 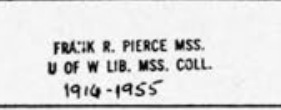 & $\begin{array}{c}\text { Brainend, Erastus } \\
1880-1919\end{array}$ & 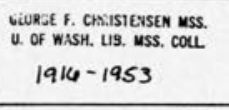 \\
\hline $\begin{array}{l}\text { MERRIL \& RING LeR. CO. RECORJS } \\
\text { U. OF WISH. UB. WSS. COLL. } \\
1909-1944\end{array}$ & $\begin{array}{c}\text { Mountaineers } \\
1906-1966\end{array}$ & $\begin{array}{l}\text { EDTH D. RIIEY MSS } \\
\text { U of W UB. MSS. COLL. } \\
1909-1964\end{array}$ \\
\hline $\begin{array}{c}\text { SEATTLE. UCHTING } \\
\text { DEPT. RECORDS } \\
\text { UW Li, MSS. COUL. } \\
1899-1938 \\
\end{array}$ & $\begin{array}{l}\text { R.LLCA A. DICKEY PAPERS } \\
\text { U of W UB. MSS. COLL } \\
1898-1940\end{array}$ & $\begin{array}{l}\text { Peoples' Savings } \\
\text { Bank 1890-1920 }\end{array}$ \\
\hline 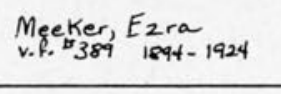 & $\begin{array}{l}\text { WALTER G. WELEN PAPERS } \\
\text { U OF W LIR. MSS. COLL. } \\
1900-1950\end{array}$ & $\begin{array}{l}\text { Mevin SWNFORO COLL. } \\
\text { uo w IB. MSS. COLI } \\
1897-1961 \\
\end{array}$ \\
\hline $\begin{array}{l}\text { WESLEY L JONES MSS. } \\
\text { Wot W UR, MSS. COLL } \\
1863-1932\end{array}$ & $\begin{array}{l}\text { Imw coul. } \\
\text { un us. uss. coul. } \\
1905-1950\end{array}$ & $\begin{array}{c}\text { Potts, Ralph B. } \\
1903-1945\end{array}$ \\
\hline $\begin{array}{l}\text { Methow Trading } C_{0} \text {. } \\
1896-1922\end{array}$ & $\begin{array}{l}\text { Pacific Northwest } \\
\text { Library Aosn } \\
\text { V.R. } 412 \text { 1914- }\end{array}$ & $\begin{array}{l}\text { Tindall, Phillip } \\
1916-1965\end{array}$ \\
\hline
\end{tabular}

years 1902 and 1919, and it also shows their location within the manuscript group (box 14, folders 1 to 18 , as in Example 11). The repository clerk can then check the Data Sheet (Example 12) of the Erastus Brainerd Manuscript group to determine its location within the repository and retrieve the file folders for the researcher.
In the example (11) shown a book index using looseleaf forms is utilized. Catalog cards can also be used, however, at greater expense. The only information needed would be the name, subject, or date at the top of the card followed by names of the pertinent manuscript groups on the body of the card. In using the card form an alternative would

\section{EXAMPLE 10}

The Erastus Brainerd Papers, 1880-1919

Name Index

Note: Starred names have been entered in the Cumulative Name Index.

Adams, John, ${ }^{\circ} 3,6,7$

Cain, Harry Pulliam, 5

Douglas, Frederick, ${ }^{\circ} 5,8$

Harris, Benjamin, 6

Jones, Wesley L., ${ }^{\circ}$ 7, 9, 12, 16
Lewis, Richard, 14, 16

March, Harry, ${ }^{\circ} 17,18$

Simpson, Howard, 34

Tyler, Francis, 49

Washington, George, ${ }^{\circ} 13,49$

\section{EXAMPLE 11}

The Erastus Brainerd Papers, 1880-1919 INCOMING LETTERS

Box/folder No.

$13 / 25$

$13 / 26$

$13 / 27$

$14 /(1-18)$

\section{Name}

Chadwick, Stephen J.

Dilling, George

Hoge, James

Jones, Wesley L.
Inclusive

dates No. of items

1896-1918 38

1908-1911 3

1902-1916 $\quad 10$

1902-1919 $\quad 115$ 
EXAMPLE 12

1. Name of accession BRAINERD, Erastus, 1855-1922

2. Type of material_Correspondence, mainly incoming letters, with some

3. Location A I A $6 / 2-3$

4. Size ca. 2900 items

5. Source Bequest of The Brainerd Estate, June 1922.

6. Biographical features:

See :

1. University of Washington Library, Manuscript Series, \#2. (1960)

2. Who Was Who, v. 1.

3. Dictionary of American Biography

See also Microfilms A 1698, A 921 in Newspapers-Microcopy Section

7. Names of major correspondents:

See inventory

8. Special restrictions:

none

9. Literary property rights:

In public domain

10. Subjects covered:

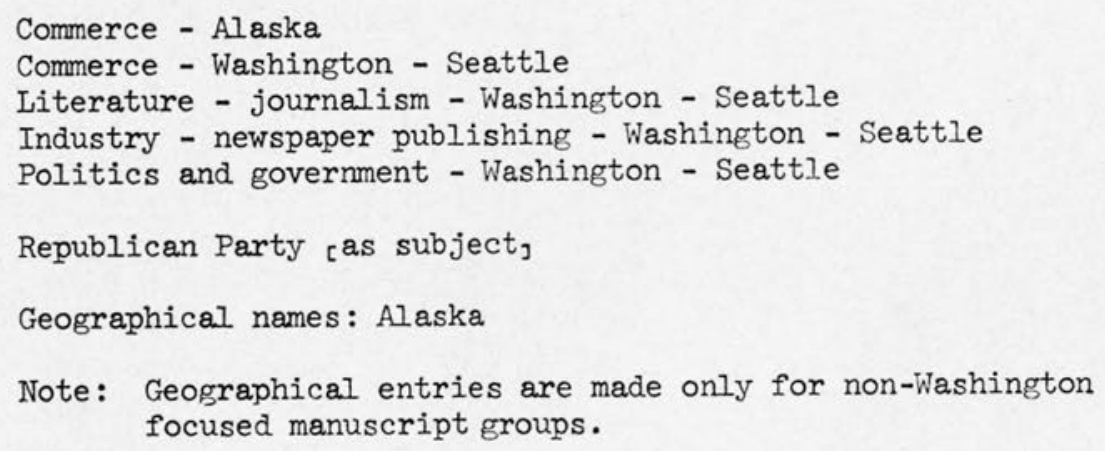


be to make a fresh card for each entry. Once the main entry is established a unit card for the manuscript group could be multilithed and used for making added entries.

In the network system outlined above it is clear that a high degree of name control is established. Furthermore, that control is not dependent on the arrangement of the manuscript group; whatever the arrangement is, it can be described. In addition, it is keyed normally to the file folder for the correspondence series, to the record series itself for most other series, and to the manuscript group level for general subject matter. The bibliographic search is thereby simple, direct, and objective. It proceeds, in fact, in much the same way as machine retrieval and is similarly free of narrative descriptive apparatus, because that kind of description is unnecessary in this system. For this reason it is also relatively less expensive than methods that depend on minute subject analysis, and in which the card catalog is the main finding aid. A great saving is made by avoiding the use of relatively expensive catalog cards with attendant typing and filing of individual cards that frequently repeat information. Instead, loose- leaf sheets are filed in post-binders for each of the cumulative indexes; on these looseleaf sheets only the names of the pertinent groups are posted. For the researcher it is a simple, direct system much like that of NUCMC in which skeletal name, subject, and temporal leads are followed step by step to the manuscript material itself. There is an inexpensive way of adapting it to an existing card catalog system. Adaptation is easiest for names. The problem is to refer the user of the card catalog to the manuscripts reference service for material with which a given name is identified. Assuming that name already appears in the catalog, all subsequent references need to be placed on one card only in the catalog for that name. That card can read:

Jones, Wesley Livsey (1863-1932) For other references to this name inquire at Service Desk.

Subject headings could be handled similarly, although this in turn would depend on the kind of subject headings the repository decides to employ and to what record levels they refer. Chronology poses no special problem.

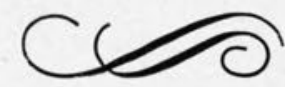

